\title{
Perfil dos envolvidos na captura e comercialização de tubarões em um polo pesqueiro do litoral amazônico
}

\section{Profile of those involved in the capture and commercialization of sharks at a fishing pole on the Amazonian coast}

\author{
Renan Fernando Conde Rosa, Carlos Eduardo Rangel de Andrade* \& Luciano de Jesus Gomes Pereira \\ Instituto de Estudos Costeiros, Universidade Federal do Pará - UFPA
}

*E-mail: eduardora@ufpa.br

Recebido: 7 de julho de 2017 / Aceito: 10 de agosto de 2017 / Publicado: 8 de dezembro de 2017

Resumo O presente trabalho tem como finalidade, caracterizar a pesca de tubarões e a cadeia de comercialização de seus produtos, no município de Bragança, estado do Pará, assim como apresentar informações mais fidedignas à obtenção de dados, tendo em vista a sua inconsistência e carência. O estudo foi realizado, entre os meses de junho e outubro de 2015. Inicialmente, para a coleta de informações, foram feitas diversas incursões junto a Secretaria Municipal de Economia e Pesca (Semep). Posteriormente para a realização desse manuscrito, o trabalho foi dividido em duas etapas complementares. A primeira foi realizada em dois locais (Vila dos pescadores e Centro de Bragança), contemplando os pescadores envolvidos na pesca de tubarões, utilizando a técnica "bola de neve" (snowball). A segunda etapa foi realizada em três locais (Mercado municipal de Bragança unidade-centro, unidademorro e Feira-Livre), onde foi aplicado a técnica survey. As principais espécies capturadas pertencem ao gênero Sphyrnidae, conhecidos popularmente como "cação-panã". Sendo identificado duas principais formas de comercialização, in natura e abas (nadadeiras). O preço das Abas demostrou aparente queda, fator que pode estar ligado a intensificação da fiscalização pelos órgãos competentes. A pesca de tubarões no município está em ampla atividade de operação, como pode ser visto nos entrepostos de comercialização do município.

Palavras-Chave: Elasmobrânquios, Bola de neve, Comércio.

\begin{abstract}
This study aims to characterize the fishing of sharks and the supply system of their products in the city of Bragança, Pará State, as well as provide more reliable information to data collection, with a view to their inconsistency and lack. The study was conducted between June and October 2015. Initially, to collect information, several raids were made at the City office of economy and fisheries (Semep). Subsequently to the completion of this manuscript, the work was divided into two complementary steps. The first was held in two locations (village of fishermen and Bragança Center), comprising fishermen engaged in fishing sharks, using the "snowball" technique. The second stage was carried out in three locations (Bragança Municipal Market unit-center, drive-hill and street commerce), which was applied to the survey technique. The principal species belong to the genus Sphyrnidae, popularly known as "Pana shark". It is identified two main forms of marketing, "in nature" and fins. The price of fins demonstrated apparent fall, a factor that may be linked to increased by the competent supervision. Fishing for sharks in the city is in wide operating activity, as can be seen, in the city's marketing warehouses.
\end{abstract}

Keywords: Elasmobranchs, Snow ball, trade. 


\section{Introdução}

Segundo a FAO (Food and Agriculture Organization of the United Nations), o consumo de pescado tem crescido, tanto pelo aumento da demanda, quanto pelas mudanças no hábito alimentar da população global, que vem, exigindo produtos com perfil nutricional de qualidade adequado (FAO, 2014).

A utilização dos recursos pesqueiros é uma atividade de suma importância, no contexto de desenvolvimento social. Entre outros fatores, por estar dentre as principais fontes de aquisição de proteína animal, e pelas questões econômicas que a circundam, em toda a sua cadeia de produção e comercialização (Furtado, 1997).

Em geral, as modalidades de pesca empregadas na costa Norte brasileira, são principalmente artesanais, sendo reduzidas as modalidades tidas como industriais. Em muito devido aos equipamentos e facilidades utilizadas nas frotas assim denominadas, longe de serem comparáveis com as frotas da indústria pesqueira em outras regiões do país (Isaac, 2006).

Notadamente o litoral Nordeste paraense, não se faz diferente a essa realidade, onde a pesca constitui uma importante atividade econômica, de um modo geral os envolvidos na atividade, têm e vêm no uso dos recursos pesqueiros, a possibilidade de exploração comercial, de forma a garantir sua manutenção social (Braga, 2002).

A pesca no Pará, passou por um momento de significativas mudanças, seja pela migração de frotas oriundas de outros estados (Fonteles-Filho, 2011), e/ou incentivos governamentais, que permitiram a uma gama de embarcações tecnologia, para exercer suas atividades sobre recursos inatingíveis anteriormente (Espírito Santo, 2012). Dentre as espécies de peixes capturados por essa forma de organização, o grupo dos tubarões, tornaram-se importantes na região, após o estado de sobre-explotação dos estoques do Nordeste do Brasil (Braga et al., 2006).

Os tubarões são peixes cartilaginosos e junto com as raias formam a subclasse Elasmobrânchii, com aproximadamente 1.100 espécies conhecidas em todo o mundo (Compagno, 2001). Representam uma importante fonte na obtenção de produtos e produtos para o homem, principalmente carne e abas (nadadeiras) (Last \& Stevens, 2009).

Segundo Camhi et al. (1998), a maior ameaça a estes animais em meio natural é representada pela atividade antrópica. Em todo o mundo, populações de elasmobrânquios se encontram em estado de redução drástica de seus estoques, a que muito se deve à atividade de pesca. Essa redução ocorre principalmente, pela degradação do habitat desses organismos, captura acidental (by-catch) e/ou dirigida, aumento do esforço de pesca e estratégia de vida das espécies.

Atualmente, existe um verdadeiro lapso de informações acerca da captura e desembarque de barbatanas no Brasil e em especial na região norte, seja pela dificuldade de acesso as áreas de desembarque, seja pela impossibilidade de se obter uma representativa amostra de toda a região.

Segundo as estatísticas oficiais, as barbatanas se encontravam como um dos principais produtos exportados pelo Brasil em meados dos anos 2000. Somando em 2006 um volume total de $117.830 \mathrm{Kg}$ e no ano de 2007, um significativo aumento na ordem de $130.812 \mathrm{Kg}$ (Ibama, 2007).

Ainda nesse contexto em um panorama mundial, as capturas de tubarões se mantem em ascensão desde 2005, até os tempos atuas, tendo uma produção estimada em 520 t (FAO,2014).

Dentre todas as adversidades que implicam na falta de controle sobre esse grupo, os modelos contemporâneos empregados na administração de pescarias tradicionais, não se aplicam a elasmobrânquios, o que torna extremamente difícil gerenciar esse recurso (Bonfil, 1994).

De um modo geral no Brasil como em outros países, a pesquisa não caminha na mesma velocidade do aumento de esforço pesqueiro. Muito devido a inexistência de uma política conservacional para o grupo (Kotas et al., 1995; Vooren, 1997). Fazendo-se assim, necessárias pesquisas com esses indivíduos, de forma a promover o maior conhecimento sobre os mesmos.

O presente trabalho tem por objetivo, caracterizar a captura e a comercialização de tubarões no município de Bragança-Pará. Segundo a FAO (Food and Agriculture Organization of the United Nations), o consumo de pescado tem crescido, tanto pelo aumento da demanda, quanto pelas mudanças no hábito alimentar da população global, que vem, exigindo produtos com perfil nutricional de qualidade adequado (FAO, 2014).

A utilização dos recursos pesqueiros é uma atividade de suma importância, no contexto de desenvolvimento social. Entre outros fatores, por estar dentre as principais fontes de aquisição de proteína animal, e pelas questões econômicas que a circundam, em toda a sua cadeia de produção e comercialização (Furtado, 1997).

Em geral, as modalidades de pesca empregadas na costa Norte brasileira, são principalmente artesanais, sendo reduzidas as modalidades tidas como industriais. Em muito devido aos equipamentos e facilidades utilizadas nas frotas assim denominadas, longe de serem comparáveis com as frotas da indústria pesqueira em outras regiões do país (Isaac, 2006). 
Notadamente o litoral Nordeste paraense, não se faz diferente a essa realidade, onde a pesca constitui uma importante atividade econômica, de um modo geral os envolvidos na atividade, têm e vêm no uso dos recursos pesqueiros, a possibilidade de exploração comercial, de forma a garantir sua manutenção social (Braga, 2002).

A pesca no Pará, passou por um momento de significativas mudanças, seja pela migração de frotas oriundas de outros estados (Fonteles-Filho, 2011), e/ou incentivos governamentais, que permitiram a uma gama de embarcações tecnologia, para exercer suas atividades sobre recursos inatingíveis anteriormente (Espírito Santo, 2012). Dentre as espécies de peixes capturados por essa forma de organização, o grupo dos tubarões, tornaram-se importantes na região, após o estado de sobre-explotação dos estoques do Nordeste do Brasil (Braga et al., 2006).

Os tubarões são peixes cartilaginosos e junto com as raias formam a subclasse Elasmobrânchii, com aproximadamente 1.100 espécies conhecidas em todo o mundo (Compagno, 2001). Representam uma importante fonte na obtenção de produtos e produtos para o homem, principalmente carne e abas (nadadeiras) (Last \& Stevens, 2009).

Segundo Camhi et al. (1998), a maior ameaça a estes animais em meio natural é representada pela atividade antrópica. Em todo o mundo, populações de elasmobrânquios se encontram em estado de redução drástica de seus estoques, a que muito se deve à atividade de pesca. Essa redução ocorre principalmente, pela degradação do habitat desses organismos, captura acidental (by-catch) e/ou dirigida, aumento do esforço de pesca e estratégia de vida das espécies.

Atualmente, existe um verdadeiro lapso de informações acerca da captura e desembarque de barbatanas no Brasil e em especial na região norte, seja pela dificuldade de acesso as áreas de desembarque, seja pela impossibilidade de se obter uma representativa amostra de toda a região.

Segundo as estatísticas oficiais, as barbatanas se encontravam como um dos principais produtos exportados pelo Brasil em meados dos anos 2000. Somando em 2006 um volume total de $117.830 \mathrm{Kg}$ e no ano de 2007, um significativo aumento na ordem de $130.812 \mathrm{Kg}$ (Ibama, 2007).

Ainda nesse contexto em um panorama mundial, as capturas de tubarões se mantem em ascensão desde 2005, até os tempos atuas, tendo uma produção estimada em 520 t (FAO,2014).

Dentre todas as adversidades que implicam na falta de controle sobre esse grupo, os modelos contemporâneos empregados na administração de pescarias tradicionais, não se aplicam a elasmobrânquios, o que torna extremamente difícil gerenciar esse recurso (Bonfil, 1994).

De um modo geral no Brasil como em outros países, a pesquisa não caminha na mesma velocidade do aumento de esforço pesqueiro. Muito devido a inexistência de uma política conservacional para o grupo (Kotas et al., 1995; Vooren, 1997). Fazendo-se assim, necessárias pesquisas com esses indivíduos, de forma a promover o maior conhecimento sobre os mesmos.

O presente trabalho tem por objetivo, caracterizar a captura e a comercialização de tubarões no município de Bragança-Pará).

\section{Material e Métodos}

Inicialmente, foram registrados dados acerca da pesca de tubarões, junto a Secretaria Municipal de Economia e Pesca (Semep), integrante da prefeitura Municipal de Bragança, analisando a existência e atuação de embarcações que operavam na pesca de tubarões.

O presente manuscrito foi desenvolvido entre os meses de junho a outubro de 2015 e dividido em duas etapas complementares, onde as localidades analisadas, concentram os maiores registros da atividade pesqueira no município:

A primeira foi realizada em dois locais distintos Centro de Bragança (P1) e Vila dos pescadores (P2), nela se contemplou os pescadores envolvidos na pesca de tubarões, traçando o perfil socioeconômico, desses profissionais e identificando como é realizada essa atividade de pesca nessas áreas.

Para os pescadores envolvidos no cenário da pesca de tubarões, foram efetuadas entrevistas

semiestruturada, a partir de um primeiro informante/entrevistado, utilizando a técnica de amostragem não

probabilística, conhecida como "bola de neve" (snowball) Quando o entrevistado indica um próximo entrevistado e assim sucessivamente, até se chegar a um ponto de saturação, alcançado quando os entrevistados não têm mais nada de novo para apresentar. Indicada geralmente para uma população altamente especializada e de pequeno número de integrantes (Appolinário, 2006). Desta forma, se perfizeram um total de 49 entrevistas.

A segunda etapa foi realizada em três locais distintos Mercado municipal de Bragança unidade-centro (P1),

Mercado municipal de Bragança unidade-morro (P2) e Feira-Livre Municipal (P3), onde se empregou formulários a intermediários na cadeia de comercialização de produtos oriundos dos tubarões, afim de 
caracterizar essa atividade, uma vez que esses pontos concentram os principais entrepostos de comercialização de pescado no município.

Para as entrevistas dessa etapa, foi aplicado a técnica survey, pois se levou em consideração informações sobre práticas de uma população específica, durante o período amostrado, aos pontos amostrais, com aplicação de instrumento de coleta de dados de caráter qualitativo (questionários voltados ao uso do recurso pesqueiro e entrevistas semiestruturadas), Somando 21 entrevistados todos do sexo masculino, essa hegemonia masculina, deve-se ao fato de que a atividade de pesca é exercida exclusivamente por homens, tanto por uma questão cultural ou por superstição, de que as mulheres não podem, adentrarem as embarcações juntos aos homens para exercer tal atividade, essa informação é exercida historicamente comprovada na literatura.

Para o atual trabalho, foram realizadas um total de 60 entrevistas, esse total corresponde a soma das duas etapas de coletas de dados, sendo empregado ferramenta de pesquisa (questionário/formulários) semiestruturada e entrevistas formais e informais, onde na etapa 1 se questionou, sobre a dados pessoais dos pescadores (Nome, idade, estado civil, grau de instrução, tempo de exercício na atividade, tipo de residência, e sistema de pesca que opera); Dados sobre a embarcação em que exerce suas atividades, (tipo de embarcação, porto de origem, comprimento, material do casco, capacidade de estocagem, método de conservação, propulsão, tripulação, registro, tecnologia empregada e mecanização); Dimensão social (usuário de INSS, colonizado, possui seguro no defeso, carteira assinada e relação de trabalho; Dados das pescarias (duração das viagens, frequência das viagens e tipos de apetrechos utilizados) entre outros.

Quando o estudo contemplou os intermediários/comerciantes etapa 2, na cadeia de distribuição e comercialização dos produtos do tubarão, se buscou informações sobre, espécies comercializadas, preços de compra e venda da carne e abas (nadadeiras) e como e onde exercem suas atividades.

\section{IDENTIFICAÇÃO DAS ESPÉCIES CAPTURADAS}

A identificação das espécies em campo foi realizada a partir do conhecimento empírico por parte dos entrevistados, em virtude da dificuldade de acesso ao produto a ser estudado, seja por está exposto para a venda ao público e consequentemente de difícil manipulação pelo entrevistador. Ou seja, simplesmente por "medo" dos vendedores de que a intervenção (coleta de dados) fosse parte de um serviço de fiscalização dessa atividade.

Porém quando possível, a identificação e classificação dos espécimes foi efetivada com o auxílio de chave de identificação de acordo com (Compagno, 2005).

Posteriormente os questionários e as entrevistas foram sistematizados e armazenados em uma base de dados e utilizados para a elaboração de tabelas e diagramas que evidenciam percepções e discursos desses atores sobre o recurso, com o auxílio de estatística descritiva.

\section{Resultados}

\section{PERFIL DOS ENTREVISTADOS}

Pode-se traçar um perfil socioeconômico dos profissionais (pescadores, intermediários e comerciantes), atuantes no sistema da pesca de tubarões no município de Bragança.

Com relação aos pescadores, foram realizadas 49 entrevistas correspondentes a etapa 1 , onde se obteve os seguintes resultados, $100 \%$ dos entrevistados eram do sexo masculino, com idade média de 37 anos, com o mínimo de 19 e máximo de 63 anos, destes a grande maioria eram originários do Estado do Pará, 81,63\% ( $\mathrm{n}=$ 40), 16,33\% ( $\mathrm{n}=8$ ) do Maranhão e 2,04\% ( $\mathrm{n}=1)$ do Estado do Ceará. Do total 55,1\% ( $\mathrm{n}=27)$ são casados, com uma média de 3 dependentes.

Entre os entrevistados identificou-se uma baixa escolaridade, onde 26,53\% ( $\mathrm{n}=13$ ) eram sem grau de instrução formal (não frequentaram a escola), 71,43\% $(\mathrm{n}=35)$ possuíam nível fundamental incompleto (composto pelas primeiras series iniciais) e apenas $2,04 \%(\mathrm{n}=1)$ possuíam nível médio incompleto $\left(1^{\circ}\right.$ ano do ensino médio).

Do total $67,35 \%(\mathrm{n}=33)$, não exerciam outras atividades, tendo como principal e única fonte de renda e meio de vida a pesca e $32,65 \%(n=16)$ possuíam outras atividades de forma a complementar sua fonte de renda. Dos que exerciam outras atividades, $68,75 \%(n=11)$, complementavam suas rendas como diarista (qualquer forma de atividade remunerada por dia trabalhado), 18,75\% $(\mathrm{n}=3)$, na construção civil, $6,25 \%(\mathrm{n}=$ 1) com agricultura e $6,25 \%(n=1)$ como comerciário.

Em média os entrevistados, possuíam 18 anos de atuação na atividade pesqueira. Em si tratando das moradias, $81,63 \%(n=40)$ residiam em casa própria, destas $42,86 \%(n=21)$ de alvenaria e $38,78 \%(n=19)$ 
de madeira. $16,33 \%(n=8)$ em casa alugada, sendo que $8,16 \%(n=4)$ como material a madeira e $8,16 \%(n=$ 4) de alvenaria e o restante $2,04 \%(n=1)$ em casa da família de madeira.

Quando se observou a dimensão social dos entrevistados, identificou-se que em se tratando do INSS (Instituto Nacional do Seguro Social), 81,63\% $(\mathrm{n}=40)$ não possuía ou utilizava essa facilidade e somente 18,37\% $(n=9)$ utilizavam esse serviço. 79,56\% $(n=39)$ eram colonizados, destes $84,62 \%(n=33)$ pertencentes à colônia de Bragança $(\mathrm{Z}-17)$ e o restante $15,38 \%(\mathrm{n}=6)$ pertencentes à colônia de Curuçá-PA $(\mathrm{Z}-05)$.

Quando se explanou sobre seguro desemprego no defeso 83,67\% $(\mathrm{n}=41)$ dos entrevistados não possuíam e somente 16,33\% $(\mathrm{n}=8)$ gozavam desse serviço. Do total 97,96\% $(\mathrm{n}=48)$ não possuíam carteira de trabalho assinada pelos seus contratantes e só $2,04 \%(\mathrm{n}=1)$ possuía. Da organização do trabalho a qual os pescadores estavam inseridos, a supremacia dos entrevistados $83,67 \%(\mathrm{n}=41)$, exerciam suas atividades no sistema de partes, em acordo com suas funções na embarcação e $16,33 \%(n=8)$ praticavam a metodologia familiar.

Quando questionados sobre a embarcação em que trabalham, identificou-se que 79,59\% (n=39) dos entrevistados não possuíam embarcações próprias, exercendo suas atividades apenas como contratados. Destes 36,73\% ( $\mathrm{n}=18$ ), trabalhavam em embarcações BMP (Barco de Médio Porte), 38,78\% ( $=19$ ) em embarcações BPP (Barco de Pequeno Porte) e 4,08\% $(n=2)$ em CAM (Canoa Motorizada). Dos que são donos das embarcações que trabalham 20,41\% $(n=10)$, desses $6,12 \%(n=3)$ possuem embarcações BPP e 14,29\% $(\mathrm{n}=7)$ CAM.

Com relação aos Intermediários e comerciantes/feirantes dos entrepostos de pescados realizados na etapa 2 de coleta, foram realizadas 21 entrevistas, sendo que $16 \mathrm{com}$ vendedores/feirantes e cinco intermediários, todos do sexo masculino, com média de idade de 35 anos, em um intervalo de 25 a 52 anos.

Dos vendedores/feirantes, $56,25 \%(\mathrm{~N}=9)$ exerciam seus trabalhos na feira-livre de Bragança, $25 \%(\mathrm{~N}=$ 4) no Mercado Municipal de Bragança no Centro (MMB Centro), e 18,75\% ( $\mathrm{N}=3$ ) no Mercado Municipal de Bragança localizado no bairro do "Morro" (MMB-Morro). Já os intermediários exerciam suas funções no atual município de estudo.

\section{APETRECHOS UTILIZADOS NA CAPTURA DE TUBARÃO}

De acordo com os registros de campo, foram observados os seguintes apetrechos utilizados na pesca de tubarões no município de Bragança - PA (Tabela 1). Os que se destacaram entre os apetrechos citados pelos pescadores, foram o espinhel/long-line (Meia água), com 18,67\% $(\mathrm{n}=14)$ dentre as artes passivas e a rede pescadeira com 54,67 $(\mathrm{n}=41)$ das artes ativas.

Tabela 1. Principais apetrechos utilizados na pesca em Bragança, estado do Pará.

\begin{tabular}{lccc}
\hline & Apetrechos utilizados & $\mathbf{N}^{\mathbf{0}}$ de citações & $\mathbf{\%}$ \\
\hline \multirow{4}{*}{ Anzol } & Espinhel/ long-line (Fundo) & 2 & 2,67 \\
& Espinhel/ long-line (Meia água) & 14 & 18,67 \\
& Espinhel/ long-line (Superfície) & 1 & 1,33 \\
& Linha & 1 & 1,33 \\
\hline \multirow{3}{*}{ Rede móvel } & Rede de Cerco & 2 & 2,67 \\
& Rede de Espera (Fundo) & 3 & 4,00 \\
& Rede de Espera (Meia água) & 3 & 4,00 \\
& Rede de Espera (Superfície) & 4 & 5,33 \\
& Rede Pescadeira & 41 & 54,67 \\
Total Geral & Arrasto (meia água) & 4 & 5,33 \\
\hline
\end{tabular}

\section{CADEIA DE COMERCIALIZAÇÃO DOS PRODUTOS PROVENIENTES DA PESCA DE TUBARÕES}

A partir dos questionários semiestruturados aplicados, contemplando vendedores/feirantes e atravessadores (intermediários), pode-se traçar uma cadeia de comercialização de produtos dos tubarões desembarcados no município de Bragança do Pará. Sendo assim, identificando duas principais formas de comercialização, in natura seja para comercialização interna nos mercados municipais ou externa para outros municípios e até Estados, e a comercialização de Abas (barbatanas) dos tubarões, com finalidade a exportação (Figura 1). 


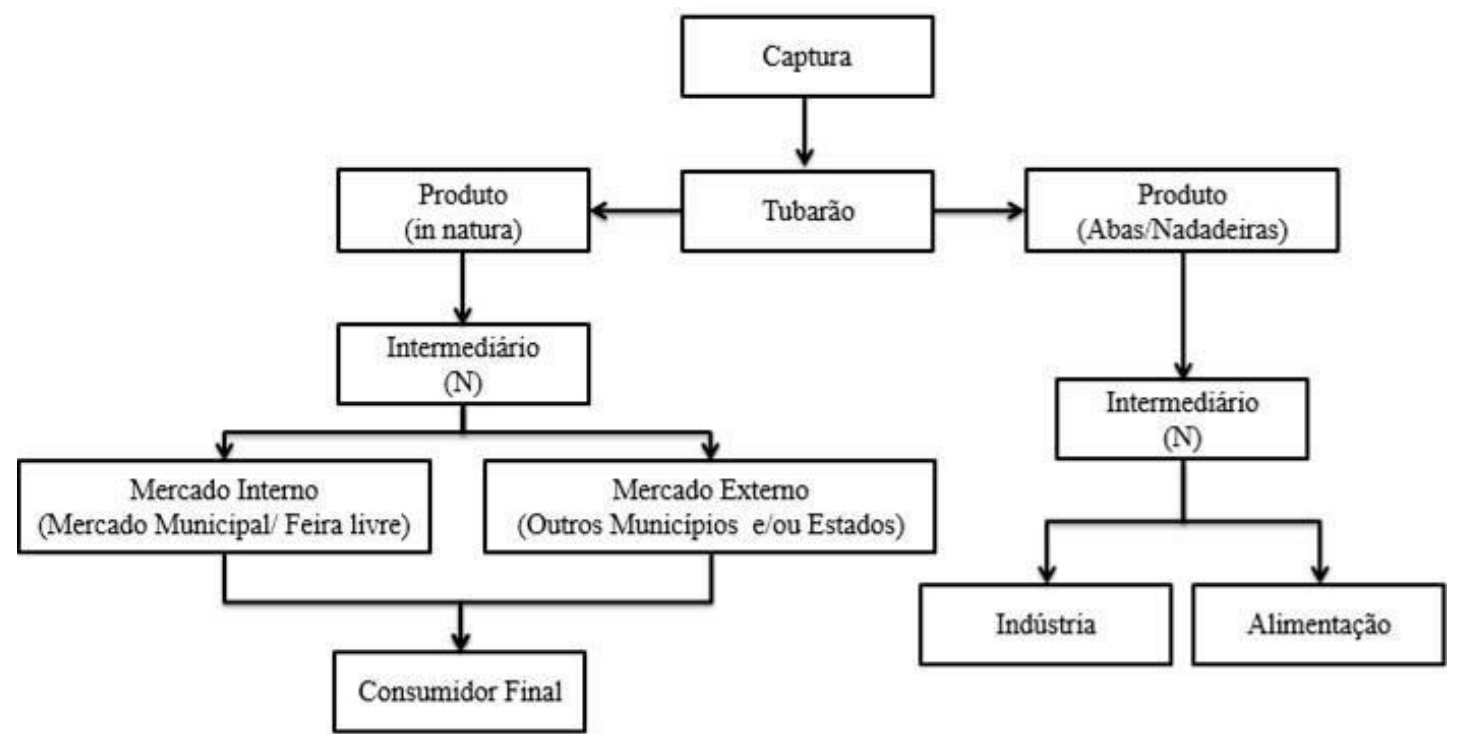

Figura 1. Fluxograma da cadeia de Comercialização dos produtos do tubarão (Adaptação própria).

No período do referido trabalho, para os cações, foram registrados preço de compra pelos vendedores/feirantes, variando entre 7,50 BRL e 8,80 BRL. Já o preço de venda para o consumidor final, variou de 9,00 BRL à 12,00 BRL. Com destaque para o cação-panã que variou principalmente em função do ponto de coleta (Tabela 2).

Tabela 2. Variação dos preços de compra e venda dos cações pelos comerciantes.

\begin{tabular}{|c|c|c|c|c|c|c|c|c|c|}
\hline \multirow{3}{*}{$\begin{array}{l}\text { Cação } \\
\text { (Etino- } \\
\text { espécies) }\end{array}$} & \multirow{2}{*}{\multicolumn{4}{|c|}{ Período de Coleta }} & \multicolumn{4}{|c|}{ Média dos preços de comercialização (BRL) } & \multirow{3}{*}{ Ponto Amostral } \\
\hline & & & & & \multicolumn{2}{|c|}{ Compra } & \multicolumn{2}{|c|}{ Venda } & \\
\hline & JUL & AGO & SET & OUT & Mínimo & Máximo & Mínimo & Máximo & \\
\hline Panã & $\mathrm{X}$ & $\mathrm{X}$ & $\mathrm{X}$ & $\mathrm{X}$ & 8,13 & 8,75 & 10,25 & 11,25 & MMB (centro) \\
\hline Panã & $\mathrm{X}$ & $\mathrm{X}$ & $\mathrm{X}$ & $\mathrm{X}$ & 7,5 & 8,8 & 11 & 12 & MMB (Morro) \\
\hline Panã & $\mathrm{X}$ & $\mathrm{X}$ & $\mathrm{X}$ & $\mathrm{X}$ & 7,6 & 8,4 & 9,4 & 10,8 & $\begin{array}{l}\text { Feira-Livre } \\
\text { (Bragança) }\end{array}$ \\
\hline Sacuri & & $\mathrm{X}$ & $\mathrm{X}$ & & 7 & 7,5 & 9 & 10 & $\begin{array}{l}\text { Feira-Livre } \\
\text { (Bragança) }\end{array}$ \\
\hline Areia & $\mathrm{X}$ & & $\mathrm{X}$ & & 7 & 8 & 9 & 10 & $\begin{array}{l}\text { Feira-Livre } \\
\text { (Bragança) }\end{array}$ \\
\hline Milho-Verde & $\mathrm{X}$ & $\mathrm{X}$ & & $\mathrm{X}$ & 7 & 8 & 9 & 10 & $\begin{array}{l}\text { Feira-Livre } \\
\text { (Bragança) }\end{array}$ \\
\hline
\end{tabular}

Para o comércio de Abas (nadadeiras), se obteve uma forma de classificação própria. A aba era selecionada não por espécie de tubarão, em virtude, principalmente, da baixa variedade específica, mas em quatro classes distintas, distribuídas por tamanho (cm) de altura (figura 2). Sendo elas: Arirú, até $10 \mathrm{~cm}$; Abinha, de 11 a 15 c; Aba média (M), de 16 a $20 \mathrm{~cm}$ e Aba grande (G) quando maior que $20 \mathrm{~cm}$ descrito como, UP pelos entrevistados, todas com preços distintos definidos pelo tamanho (Tabela 3).

Figura 2. Esquematização do dimensionamento de classificação por altura das abas.

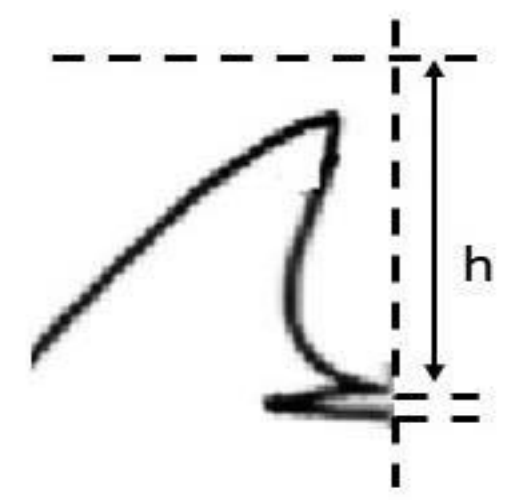


Tabela 3. Classificação de preços (BRL) por classe de tamanho $(\mathrm{cm})$, das Abas como produto.

\begin{tabular}{lccc}
\hline \multirow{2}{*}{ Nome } & \multicolumn{2}{c}{ Classe de Tamanho $(\mathrm{cm})$} & \multicolumn{2}{c}{ Preço (BRL) / Ano } \\
& & $2010 / 2011$ & 2015 \\
\hline Arirú & Até 10 & 50 a 60 & 5 a 10 \\
Abinha & 11 a 15 & 80 a 100 & 15 a 20 \\
Aba $(\mathrm{M})$ & 16 a 20 & 120 a 170 & 25 a 30 \\
Aba $(G)$ & 20 a UP & 300 a 400 & Até 100 \\
\hline
\end{tabular}

E ainda pode-se constatar uma significativa variação/queda nos preços desse produto, quando comparado os anos de 2010/2011 e o ano de 2015, considerados os anos "chave", desse comércio, para se compreender a maior disponibilização do produto "In natura" no mercado para a população em geral (figura 3).

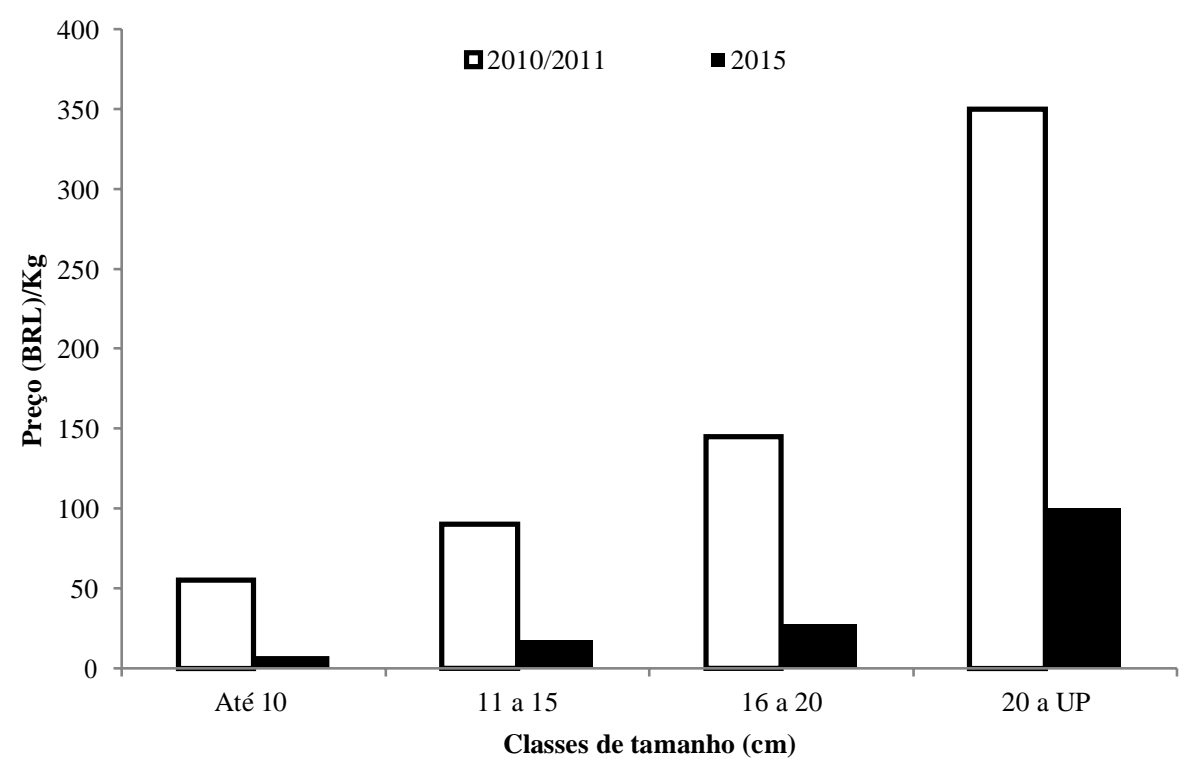

Figura 3. Variação de preços (BRL), por classe de tamanho (cm) nos anos de 2010/2011 e 2015.

\section{Discussão}

No município de Bragança, a atividade pesqueira, constitui um dos pilares da economia local, representada pela pesca industrial, artesanal de pequena e larga escala, (Espirito-Santo, 2002; Espirito-Santo \& Isaac, 2012). Nessa perspectiva, vale destacar a importância dessa atividade para a economia da região.

De uma maneira geral, a pesca de tubarões no município de Bragança-PA, não parece ser dirigida a esse grupo, desta forma, a sua significativa produção, pode estar ligada, principalmente pelo fato de estas espécies coabitarem os mesmos nichos ecológicos de alguns grupos, mais especificamente, o de alguns Scombrideos e

Scianideos. Se for levado em consideração os apetrechos de pesca utilizado comumente na captura desses peixes ósseos, pode se considerar que essas artes têm grande poder de pesca na captura de tubarões (Mourão Et Al., 2009; Silva Et Al., 2012; Espirito Santo, 2012), justificando assim o seu alto volume de desembarque.

De acordo com os resultados obtidos, sobre o perfil dos pescadores entrevistados, foi possível se observar que eles apresentam uma baixa escolaridade e deficiência no processo de profissionalização na atividade em que estão inseridos, corroborando com Alencar \& Maia (2011); Bentes et al. (2012) e Santos \& Santos (2005),

esses autores identificaram os pescadores que participam dessa atividade, em sua maioria na modalidade de partes e/ou familiar.

Esses pescadores, exercem suas atividades, com poucas inovações tecnológicas, com o emprego de conhecimentos empíricos, repassada de geração a geração por seus antecessores, sem um prévio treinamento e poucos conhecimentos biológicos sobre os recursos explorados. Dessa maneira, é notável, de maneira negativa, a influência da atividade de pesca no status das populações de elasmobrânquios na região. 
De acordo com Espirito-santo \& Isaac (2012), dentre as principais espécies capturadas, desembarcadas nos portos do estuário do rio Caeté no período de junho de 2000 a junho de 2001. O grupo dos cações apresentou uma produção de $56,4 \mathrm{t}$, representando $5,9 \%$, do montante desembarcado para a região costeira no período, destacando sua importância no volume desembarcado, para a comunidade bragantina.

Essa soma capturada está incluída no grupo, como relatado por Rodrigues-Filho et al. (2008), onde destaca que os principais tubarões (cações) explorados na costa Norte do Brasil, pertencem as espécies do gênero Sphyrna spp., com destaque para, Sphyrna tudes, Sphyrna tiburo e Sphyrna mokarran.

Acredita-se e não é difícil se notar que a atividade de pesca e revenda de tubarões na região se encontra em plena atividade, visto a grande oferta para comercialização, porém em sua grande maioria de forma clandestina, em virtude do receio de fiscalização e apreensão do produto.

A pesca de tubarões identificada no município, e similar a outras pescarias em atuação na região, quando se avalia sua estrutura, organizacional, ecológica, social e econômica, conforme descrito por Isaac et al. (2009). Muito embora seja uma prática, pouco descrita pela literatura, no que diz respeito a estatística, problema compartilhado por diversas pescarias no litoral NE do estado do Pará (Isaac et al., 2008). Durante o período em que foi realizado o referido trabalho, foi possível se acompanhar os processos de transporte, estocagem e comercialização de tubarões, com uma certa dificuldade, visto o receio dos entrevistados em responderem aos questionamentos.

Levando em consideração a pouca seletividade dos apetrechos de pesca mais representativos (as redes) no que se refere as áreas de atuação, tamanho dos exemplares capturados e a instrução normativa interministerial MPA/MMA n ${ }^{\circ} 14$, de 26 de novembro de 2012, a qual proíbe a atividade de "finning", que consiste quando o pescador retira apenas a barbatana do tubarão e descarta a carcaça do animal no mar. A realidade da pesca não parece condizer com o que é observado nos postos de revenda, onde todos os exemplares expostos para a comercialização não se encontram com suas nadadeiras, contudo são pequenos, sendo representados em sua maioria por tubarões jovens.

Braga et al. (2006), apresenta os tubarões como sendo "um pescado, não tão somente de interesse regional, mais também, para distribuição em outros estados do Nordeste e Sudeste do Brasil". A popularidade do consumo de cação no município é uma característica de destaque. Sendo assim, os principais pontos de comercialização de pescado, vem nesse argumento, uma forma potencial de relações comerciais, assim, promover a oferta desse produto (in natura) para o mercado consumidor.

No município os ambientes de comercialização, destacam-se pelos mercados municipais e feiras-livre (Freire et al., 2011). O pescado comercializado é composto em particular por peixes frescos (in natura) acondicionados em gelo, sem a utilização de metodologias aprimoradas de beneficiamento. Esses ambientes demostram a falta de uma preocupação básica com higiene, tanto por parte dos vendedores e fiscalização pela Vigilância Sanitária, para avaliação da qualidade do produto, o que acarreta riscos a população consumidora (Silva et al., 2012).

Atualmente, o cação é um pescado com significativo valor comercial visto os resultados apresentados. Essa constatação pode ter uma, íntima relação com a queda do preço de comercialização, do produto Aba/barbatanas nos últimos anos. Produto considerado mais valorizado.

O comercio de Abas/nadadeiras de tubarões, possuem regulamentação pela, portaria Ibama № $121-\mathrm{N}$, de 24 de agosto de 1998, onde estabelece as diretrizes para a pesca de tubarões e dá outras providencias sobre seus produtos (Brasil, 1998). A forte demanda por esses produtos, causam sérios impactos nas populações de tubarões em todo o mundo (Silvério, 2010; Rocha, 2013).

O mercado de barbatanas (Abas) de tubarões está interligado com o comercio de grude no município de Bragança, onde a ligação entre esses produtos e realizada pelos intermediários (atravessadores), ou seja, é a mesma pessoa que trabalha com os dois produtos. E ainda providenciam a exportação para outros estados e até países principalmente da Ásia. Sendo tanto para alimentação, como para a indústria (Leitão \& Sousa, 2006).

Como apresentado nos resultados, em relação ao preço das abas (barbatanas) apresenta aparente queda, encontrada nos anos amostrados 2010/2011 e 2015. Esse fato pode estar ligado a intensificação da fiscalização,

por intermédio do Instituto Brasileiro do Meio Ambiente e dos Recursos Naturais Renováveis (Ibama), em coibir e atuar, práticas ilícitas nesse sistema.

No ano de 2011, o órgão efetuou a primeira apreensão de uma embarcação no gênero, com 120 tubarões pescados ilegalmente na costa paraense. Ainda no mesmo ano, o Ibama em parceria com a Universidade Estadual Paulista (Unesp-Botucatu) comprovou cientificamente as fraudes praticadas por uma empresa na exportação de barbatanas no Estado. Nessa ocasião a carga apreendida, foi de 3,3 t de abas em 2010. Já em 2012 foi efetuada a maior apreensão do produto já realizada no país, um montante de 7,7 t de barbatanas, em uma empresa de beneficiamento e exportação de pescado, localizada na capital do estado (Publicações Ibama). 
As apreensões, decorrem principalmente por falta de comprovação que a carcaça do respectivo espécime foi vendida, o que caracteriza a prática do "Finning" (Kotas, 2004; Napoleão, 2014). O que tornam pouco viável do ponto de vista econômico para os empresários de pesca, o comércio de Abas (barbatanas) de tubarões, através do risco de elevadas multas e apreensão do material, sendo preferível a comercialização do produto in natura.

Em um contexto geral não a no mundo um país, envolvido em pesca sem investimento em ciência e tecnologia. O Brasil não seria diferente. Desta forma a presente pesquisa vêm a sugerir trabalhos, que levem ao acesso estatístico dos desembarques de tubarões para que medidas mitigadoras possam vir a ser tomadas.

\section{Conclusões}

A pesca de tubarões no município de Bragança-PA, está em ampla atividade de operação, haja visto que encontrar-se associada a outros sistemas pesqueiros, segundo relatado pelos entrevistados. A embarcação sai do porto, com a finalidade de capturar uma dada espécie, mais para compensar os gastos nesse processo, os tubarões se tornam uma alternativa.

Acredita-se que o material observado na presente pesquisa é somente uma parte insignificante do que realmente é capturado, já que a carne de tubarão é um produto, não apenas de interesse local. Mas também um produto de grande aceitação em outros municípios, estados e até países. Sendo que esses, são retirados da embarcação diretamente para os veículos de transporte, com destinatário previamente certo.

Ainda segundo relato dos entrevistados, o que é vendido nos pontos de comercialização de pescados do município, em sua maioria é o que não atendeu aos padrões, de outras localidades consumidoras.

Essa atividade em atuação no município, é justificada pelo forte fornecimento de seu produto "carne", nos pontos de comercialização. Onde a mesma possui déficit de informações no que se refere a séries históricas de estatística pesqueira, em muito devido à dificuldade de classificação dos indivíduos. Já que em sua maioria os tubarões, desembarcados nos portos, já vem descabeçados e sem a presença de suas nadadeiras (barbatanas).

Os tubarões comercializados no município, estão inclusos no grupo dos cações, e as principais espécies capturadas pertencem ao gênero Sphyrnidae, conhecidos popularmente como cação-panã. A característica principal de identificação desses espécimes pelos entrevistados, deve-se ao formato de sua cabeça, uma espécie de martelo. Sendo que o preço do produto in natura, demostrou elevado preço, nos entrepostos de comercialização nos dias atuais.

Foi identificada uma forma própria de classificação das abas (barbatanas), entre os atores envolvidos nesse processo (pescadores/intermediários). Uma vez que a aba é selecionada não por espécie de tubarão, mas em quatro classes distribuídas por tamanho (cm), denominadas de arirú, abinha, aba média (M) e aba grande (G).

De acordo com os dados e resultados obtidos na presente pesquisa, demostraram que atualmente há pouca atratividade no comércio de abas (nadadeiras), visto a significativa queda no seu preço de comercialização, tendo como possível motivação, a intensificação da fiscalização por parte dos órgãos competentes nos meios de produção e distribuição.

\section{Agradecimentos}

A todos os entrevistados (pescadores, intermediários e comerciantes), pela gentileza de prestar melhores informações, a respeito das atividades em que estão inseridos, sem elas não seria possível a realização do presente manuscrito.

\section{Referências}

Alencar, C. A. G. \& Maia, L. P. (2011). Perfil socioeconômico dos pescadores brasileiros. Arq. Ciên. Mar, 44(3): 66-73.

Almeida, Z. S., Isaac, V., Santos, N. B. \& Paz, A. C. (2010). Diagnóstico dos sistemas de produção pesqueiro artesanais do litoral do Maranhão. São Luís: Editora Uema.

Alves, M. A. M. S. (2001). Morfodinâmica e Sedimentologia da Praia de Ajuruteua-NE do Pará.

[Dissertação de Mestrado]. Belém (Pa): Universidade Federal do Pará.

Appolinário, Fábio. (2006). Metodologia da ciência: filosofia e prática da pesquisa. São Paulo. Thomson

Learning, 226 pp. Editor Cengage 
Barthem, R. B. (1992). Desenvolvimento da pesca comercial na bacia amazônica e consequiências para os estoques pesqueiros e a pesca de subsistência. In: L. E. Aragón (ed.). Desenvolvimento sustentável nos trópicos úmidos. Belém: Unamaz/UFPA.

Bentes, B., Cañete, V. R., Pereira. L. J. G., Martinelli-Lemos, J. M., \& Isaac, V. 2012. Descrição socioeconômica da pesca do camarão Macrobrachium amazonicum (Heller, 1862) (Decapoda: Palaemonidae) em um estuário da costa norte do Brasil: o caso da ilha do mosqueiro (PA). Boletim do Laboratório de Hidrobiologia, 25(1).

Bentes, B., Isaac, V. J., Espírito-Santo, R. V., Frédou, T., Almeida, M. C., Mourão, K. R. M. \& Frédou, F. L. (2012). Multidisciplinary approach to identification of fishery production system on the northen coast of Brazil. Biota Neotrop., 12(1): 81-92.

Bonfil, R. (1994). Overview of world elasmobranch fisheries. FAO Fisheries Technical Paper, $\mathrm{N}^{\circ} 341$.

Braga, C. F. A. (2002) Atividade pesqueira de larga escala nos portos de desembarque do rio Caeté, Bragança, PA. Dissertação de Mestrado. Universidade Federal do Pará, 60 pp.

Braga, C.F.; Espírito-Santo R.V., Silva, B.B., Giarrizzo, T. \& Castro, E.R. (2006). Considerações sobre a comercialização de pescado em Bragança - Pará. Bol. Téc. Cient. Cepnor, Belém 6: 105-120.

Brasil - Instrução normativa interministerial MPA/MMA n ${ }^{\circ}$ 14, de 26 de novembro de 2012. Dispõe sobre normas e procedimentos para o desembarque, o transporte, o armazenamento e a comercialização de tubarões e raias. Extraído de [DOU 28/11/2012 - Seção 1: 34-35], acesso em 21/10/2015.

Brasil - Portaria Ibama n ${ }^{\circ} 121-\mathrm{N}, 24$ de agosto de 1998. Dispõe sobre a pesca e transporte de tubarões e seus subprodutos e dá outras providencias. Extraído de [http://www.icmbio.gov.br/], acesso em 20/10/2015.

Camhi, M., Fowler, S., Musick, J., Bräutigam, A., Fordham. S. (1998). Sharks and their Relatives Ecology and Conservation. Occas. Pap. IUCN Spec. Survival Comm. №. 20.

Compagno, L. J. V. (2001). FAO species catalogue Vol. 2. Sharks of the world. Bullhead, mackerel and carpet sharks (Heterodontiformes, Lamniformes, and Orectolobiformes). FAO Species catalogue for Fishery Purposes. No. 1, Vol. 2. Rome: FAO.

Compagno, L. J. V., Dando, M., \& Fowler, S. (2005). A field guide to sharks of the world. London: Collins.

Espírito Santo, R. V. \& Isaac, V. J. (2012). Desembarques da pesca de pequena escala no município de Bragança-PA, Brasil: Esforço e Produção. Boletim do Laboratório de Hidrobiologia, 25(1): 31-48.

Espírito Santo, R. V. (2992). Caracterização da atividade de desembarque da frota pesqueira artisanal de pequena escala na região estuarina do rio Caeté, Município de Bragança - Pará- Brasil. Dissertação de Mestrado. Universidade Federal de Pará.

FAO. 2014. El estado mundial de la pesca y la acuicultura 2014. Roma. 253 pp.

Fonteles-Filho, A. A. (2011) Oceanografia, biologia e dinâmica populacional de recursos pesqueiros. Expressão Gráfica e Editora, Il.color broch.

Freire. J. L, Silva. B. B. \& Souza. A. S. (2011). Aspectos Econômicos e Higiênico-Sanitários da Comercialização do Pescado no Município de Bragança (PA). Biota Amazônia, 1(2): 17-28.

Furtado, L. (1997). Ocupação humana no litoral amazônico. Belém: [s.n].

Ibama. Estatística pesqueira 2007. Grandes regiões e unidades da federação. Acessado em http: //www.ibama.gov.br.

Ibama (2015). Acessado em http://www.ibama.gov.br/publicadas/ibama-apreende-mais-de-7-toneladas-debarbatanas-de-tubarao-pescadas-ilegalmente-no-para.

Ibama (2015). Acessado em http://www.ibama.gov.br/publicadas/pesquisa-comprova-cientificamente-fraudena-exportacao-de-barbatanas-de-tubarao-no-para.

Ibama (2015). Acessado em http://www.ibama.gov.br/publicadas/barco-com-120-tubaroes-pescadosilegalmente-e-apreendido-na-costa-do-para.

Isaac, V, J., Espirito Santo, R. V. \& Nunes, J. L. G. A. (2008). Estatística pesqueira no litoral do Pará: Resultados divergentes. Pan-American Journal of Aquatic Sciences. 3(3): 205-213.

Isaac, V.J. (2006). Explotação e manejo dos recursos pesqueiros do litoral amazônico: um desafio para o futuro. Ciência e Cultura, São Paulo, 58(3): 33-36.

Isaac, V.J., Espírito Santo, R.V., Silva, B.B, Frédou, F. L., Mourão, R. M. \& Frédou, T. (2009). An interdisciplinar evaluation of the Fishery Production Systems off the Para State, Brazil. Journal of Applied Ichthyology. 25(3): 244-255.

Kotas, J. E. (2004). Dinâmica de populações e pesca do tubarão-martelo Sphyrna lewini (Griffith \& Smith, 1834), capturado no mar territorial e zona econômica exclusiva do sudeste-sul do Brasil. Tese de Doutorado. Universidade de São Paulo. 
Kotas, J.E., Gamba, M.R., Conolly, P.C., Hostim, S. M., Mazzoleni, R.C. \& Pereira, J. (1995). A pesca de emalhe direcionada aos elasmobrânquios com desembarques em Itajaí/SC. Itajaí/Relatório técnico Cepsul/Ibama.

Last, P. R. \& Stevens, J. D. (2009). Sharks and rays of Australia, 2nd edition. CSIRO Division of Fisheries, Melbourne, Australia.

Leitão, W., \& Sousa, I. S. (2006). Pescadores insulares e mercados: aspectos das relações de reciprocidade no comércio de pescado no Pará. Boletim do Museu Paraense Emílio Goeldi. Belém: Museu Paraense Emílio Goeldi. Bol. Mus. Para. Emílio Goeldi. Ciências Humanas, Belém, 1( 2): 53-64.

Mourão, K. R. M., Frédou, F. L., Espírito Santo. R. V., Almeida, M. C., Silva, B. B., Frédou, T. \& Isaac, V. (2009) Sistema de produção pesqueira pescada amarela-Cynoscion acoupa Lacèpede (1802): um estudo de caso no litoral nordeste do Pará-Brasil. Bol. Inst. Pesca, São Paulo, 35(3) 497-511.

MPA - Ministério da Pesca e Aquicultura. (2013). Boletim estatístico da pesca e aquicultura - Brasil, 2011, (versão final) $60 \mathrm{pp}$.

Napoleão, S. R. (2014). Descrição da fauna parasitária de raias e tubarões marinhos (Elasmobranchii), fauna acompanhante da pesca comercial no litoral Sul e Sudeste do Brasil. Tese de Doutorado, Universidade Estadual Paulista, Faculdade de Ciências Agrárias e Veterinárias de Jaboticabal. Disponível em: <http://hdl.handle.net/11449/110621>. 80 pp.

Rocha, M. L. N. (2013). Desenvolvimento de marcadores genéticos para identificação de espécies de tubarões comercializados no Brasil. Dissertação de Mestrado, Universidade Estadual Paulista Júlio de Mesquita Filho, Instituto de Biociências de Botucatu. Disponível em: http://hdl.handle.net/11449/95071.

Rodrigues-Filho, L.F.S., Rocha, T. C., Rego, P.S., Schneider, H., Sampaio, M. I. C. \& Vallinoto, M. (2008). Identificação molecular do estoque de cações (tubarões) explorados na costa norte do Brasil: implicações para conservação.

Santos, G. M. \& Santos, A. C. M. (2005) Sustentabilidade da pesca na Amazônia. Estudos avançados. 19(54): 165-182.

Silva, E. S. C., Cunha, D. S., Araújo, C. S. P., Sales, A. D., \& Holanda, F. C. A. F. (2012) Cadeia de comercialização do pescado desembarcado no posto fiscal de Bragança, Estado do Pará. Arq. Ciên. Mar, 45(1): 82 - 87.

Silva, N. R., Azevedo, A. \& Ferreira, M. I. P. (2012). Gestão dos recursos pesqueiros no Brasil e panorama da pesca artesanal em Macaé, RJ. Boletim do Observatório Ambiental Alberto Ribeiro Lamego, Campos dos Goytacazes/RJ, 6(2) 37-58.

Silvério, J. (2010). Identificação genética de espécies de tubarões e monitoramento da pesca no litoral de São Paulo. Dissertação de Mestrado. Universidade Estadual Paulista, Instituto de Biociências de Botucatu. Disponível em: http://hdl.handle.net/11449/99425.

Vooren, C. M. (1997). Demersal elasmobranchs. In: Seeliger U., Odebrecht, C. \& Castello, J.P. eds. Subtropical Convergence Environments. The Coast and Sea in the Southwestern Atlantic. Berlin, Springer Verlag: 141-145. 